\title{
Knowledge, Attitude and Practice towards Smoking among International Islamic University Malaysia Kuantan Communities
}

\author{
Nurul 'Izzati $A H^{\mathrm{a}}$, Nor Azlina $A R^{\mathrm{b}}$, Nor Iza $A R^{\mathrm{c}}$, Mainul $\mathrm{H}^{\mathrm{d}}$ \\ ${ }^{a}$ Graduate of Biomedical Science, Kulliyyah of Science, IIUM. \\ ${ }^{b}$ Department of Biomedical Science, Kulliyyah of Allied Health Sciences, International Islamic University \\ Malaysia. \\ 'Unit of Pathology, Faculty of Medicine, Universiti Sultan Zainal Abidin. \\ ${ }^{d}$ Unit of Pharmacology, Faculty of Medicine and Defense Health, National Defense University of Malaysia
}

\begin{abstract}
Smoking is an issue that has spread around the world throughout the years. The majority of smokers have the intention to quit smoking, but due to some factors, it may prevent their intention. Research and interventions have been done in many countries to decrease the smoking prevalence. This cross-sectional study aimed to find out the associations of knowledge, attitude and practice (KAP) towards smoking and to identify the factors associated with knowledge and attitude towards smoking, in priority to sociodemographic factors among the International Islamic University Malaysia Kuantan (IIUMK) communities, including between students and workers. One hundred fifteen respondents of students and workers from IIUMK were investigated with a self-administered questionnaire starting from 10-01-2014 to 10-02-2014. The data were analysed using SPSS software. Respondents had good knowledge and practice, and moderate attitude towards smoking. There was weak positive correlation between knowledge with attitude $(r=+0.193$, $p=0.038)$ and practice $(r=+0.206, p=0.028)$, also moderate correlation between attitude and practice towards smoking $(r=+0.626, p<0.001)$. There was no factor found to be associated with knowledge, but significant association was found between attitude towards smoking with gender $(p<0.001)$, education level $(p=0.016)$ and smoking status $(p<0.001)$. Although, the mean values of KAP levels were higher for workers, but it was not statistically significant as compared to the students. These study findings suggested that the main obligation are more for students to improve their KAP level towards smoking as they are fresh generation who will educate and lead the upcoming generation of Malaysia.
\end{abstract}

KEYWORDS: Health Knowledge, Attitudes, Practice, Smoking, Students, Workers.

\section{INTRODUCTION}

Tobacco smoking is a well-known practice for human being as early as 5000-3000 BC. Numerous studies all over the world have concluded that smoking is a cause of many preventable diseases. Smoking related diseases are among the top killer for the past three decades. ${ }^{1}$ However, smoking remains high in developing countries as there are a lot of promotional activities by the tobacco companies in the developing countries, ${ }^{2}$ and majority of the smokers in the world live in the low and middleincome countries. ${ }^{3}$ Smokers not only damage themselves but also causing damages to the people surrounding them. The harm from tobacco smoking

Nor Azlina A. Rahman

Assistant Professor

Department of Biomedical Science

Kulliyyah of Allied Health Sciences

IIUM Kuantan Campus

Tel Office : 09-5705207

$H / p: 019-9106337$

Email: nazara@iium.edu.my

Alternate email: nazara71@gmail.com is similar to communicable diseases which shows no limitation in geographical or political boundaries. ${ }^{2}$ Although the prevalence of smoking has declined, ${ }^{4}$ the reasons of smoking still remain imprecise and it is still the primary cause of death in Malaysia and many other countries. ${ }^{5}$

One-third of adult population smoke even though tobacco kills more people than suicide, AIDS, alcohol and others. ${ }^{6}$ The second-hand smoking effect is associated with lung cancer and asthma in adults, and ear infections and bronchitis in children. ${ }^{7}$ World Health Organisation (WHO) recently reported that tobacco 'kills up to half of its users', which are about six million people yearly. ${ }^{3}$ It also reported that 'more than five million of those deaths are the result of direct tobacco use while more than 600000 are the result of non-smokers being exposed to second-hand smoke'. ${ }^{3}$ Twenty-three percent of Malaysians smoke tobacco. ${ }^{8}$ The same study reported that $90 \%$ of the respondents knew that smoking causes a number of dangerous diseases. ${ }^{8}$

Currently, societies have ample opportunity to access correct information regarding smoking and its adverse impacts. Consequently, students and 
workers at the International Islamic University Malaysia Kuantan (IIUMK) Campus should have high awareness towards the hazards of smoking. Comprehensive knowledge about smoking influences the attitude and practice towards smoking. Research report suggested that more knowledge regarding the negative effects of smoking is associated with a better attitude towards tobacco control program, although the media exposure regarding smoking does not play much role. ${ }^{7}$

The majority of smokers has the intention to abandon smoking, but some issue may inhibit their aim. ${ }^{9}$ Anti-smoking program should incorporate the decreasing demand, reducing supply, improving and broadening the surveillance, and endorsimg the exchange of scientific information to obtain the desired output. ${ }^{10}$ The mass media should highlight the negative paraphernalia of smoking including the second-hand and third-hand smoke. These contributions will lead to the implementation of strict tobacco control policy that will protect manhood from the holocausts of smoking. ${ }^{7}$ This research was done to determine the knowledge, attitude and practice (KAP) towards smoking among IIUMK communities, specifically among students and workers. We also aimed to determine the risk factors and association between the KAP.

Research Objectives: To study the KAP towards smoking among IIUMK communities. We specifically aimed (1) to determine the association between KAP towards smoking among IIUMK communities, (2) to determine the factors associated with knowledge and attitude regarding smoking among IIUMK communities, and (3) to compare the KAP regarding smoking between students and workers in IIUMK.

\section{MATERIALS AND METHODS}

This was a cross-sectional study, conducted at the IIUMK among students and workers. All IIUMK community members were eligible to participate in this survey based on the inclusion and exclusion criteria. The inclusion criteria were undergraduate students and workers on IIUMK Campus, Malaysia. Those who do not understand English or Malay language were excluded from this study. Power and Sample Size software version 3.0.43 was used to calculate the sample size, which was 115 , with the assumptions that a (significance level) $=0.05$, power $=0.8, \mathrm{~m}$ (ratio between cases and controls) $=1$, $\delta$ (detectable difference) $=0.3$ and $\sigma$ (standard deviation $)=0.81$.

The standard deviation was taken from the previous study in Nepal. ${ }^{11}$ Ten percent non-response rate were added to encounter the missing values which resulted in a total of 126 subjects. Quota sampling, by using convenience sampling in each stratum was applied in order to get the possible similar number of students and workers to validate the comparison between the two groups later.
The survey instrument, self-administered questionnaires were distributed to the respondents. The data were collected from the $10^{\text {th }}$ of January to the $10^{\text {th }}$ of February 2014. This study was approved by the IIUM Ethics Research Committee (IREC; Reference no: IIUM/310/G/20/4/14-40). Experts validated the content of the questionnaire and a pilot study was conducted for the face validity of the questionnaire. Written consent was obtained from all respondents, who enjoyed full liberty for any inquiry and help.

The questionnaire was divided into four sections (A, $B, C$, and D). Section A consists of sociodemographic variables. The data in this section include gender, age, educational level, employment status, current income status and the categories of smoking status. Section B was the knowledge regarding smoking. It consists of general knowledge regarding smoking, such as the definition of smoking, the facts regarding smoking and the common smoking related diseases. The participants were required to answer either "yes," "no" or "do not know". Section C was the attitude towards smoking that were based on the level of agreement towards smoking. It had been categorised from "strongly disagree"to "strongly agree" with a five point Likert scale; where 1=strongly disagree, 2=disagree, 3=neutral, $4=$ agree and $5=$ strongly agree. Section $D$ was the practice towards the prevention of smoking. The respondents were asked to answer based on their level of practice such as "often", "seldom" or "never". This section focused on the frequency level in practicing the steps of smoking prevention in their daily life. It had also been categorised using a three-point Likert scale where $1=$ often, $2=$ seldom, and $3=$ never.

The scoring system for each section of the questionnaire is as follows: for knowledge (only positive statements): $\mathrm{no}=0$, do not $\mathrm{know}=1$, yes=2; attitude for positive statement: totally disagree $=1$, disagree $=2$, neutral $=3$, agree $=4$, strongly agree $=5$; attitude for negative statement: totally disagree $=5$, disagree $=4$, neutral $=3$, agree $=2$, strongly agree $=1$; practice (only positive statements): never $=0,1=$ seldom, $2=$ often. The collected data were analysed using SPSS. For the first objective, correlation test was used to find the association between KAP towards smoking among IIUMK communities.

The second objective used the independent $t$ test, correlation and Kruskall-Wallis test to investigate the factors associated with knowledge and attitude towards smoking among IIUMK communities, in priority to the socio-demographic factors. The non-parametric Kruskall-Wallis test was used due to the violation of normality assumption which invalidate the use of parametric Anova test. Independent $t$-test was used to compare the KAP towards smoking between students and workers. 


\section{RESULTS}

There were 115 respondents who answered the questionnaire completely. $49.6 \%$ (57) are males and the rest are females. The age of respondents varies with the mean of $28 \pm 7.04$ years old. As a result of quota sampling, student and worker respondents were $49.6 \% \quad(57)$ and $50.4 \% \quad(58)$ respectively. According to the academic status, there were $24.3 \%$ (28), $18.3 \%$ (21) and $57.4 \%$ (66) respondents from secondary school level, diploma and bachelor's degree levels respectively. Only 7\% (8) student respondents were totally dependent on parents, whereas $42.6 \%$ (49) student were under bank loan or scholarship. The rest of the respondents were workers where $14.8 \%$ (17), $28.7 \%$ (33) and $7.0 \%$ (8) of them had a salary of less than RM1000, RM1000 RM3000 and RM3000-RM5000 respectively. Finally, regarding smoking habit, $73.0 \%(84), 18.3 \%$ (21) and $8.7 \%(10)$ of the respondents were nonsmokers, current smokers and former smokers, respectively.

Determining the levels of KAP towards smoking The mean and standard deviation for knowledge, attitude and practice scores were $21.8 \pm 3.45,86.1 \pm$ 13.7 and $12.6 \pm 4.75$, respectively. Majority or $63.5 \%$ (73) of the respondents have good knowledge scores (22-26) regarding smoking while $34.8 \%(40)$ and $1.7 \%$ (2) had moderate (11-21) and poor (0-10) knowledge levels respectively. Only $1.7 \%$ (2) have good scores (105-158) regarding attitude towards smoking, with most of them or $91.3 \%$ (105) have moderate scores $(65-104)$, while the rest $7 \%$ (8) possess poor $(0-64)$ attitude towards smoking. On the other hand, about half of the respondents or $48.7 \%$ (56) have good practice scores (14-20), followed by $39.1 \%$ (45) of moderate (7-13) and only $12.2 \%$ (14) of poor (1-6) practice scores towards smoking.

\section{Association between KAP towards smoking}

Pearson correlation test was used to determine the relationship between knowledge with attitude and practice scores towards smoking. On the other hand, Spearman correlation test was used to determine the association between attitudes and practice scores towards smoking due to the non-assumption of normal distribution. All the $p$-values were found to be less than 0.05 ; which are 0.038 for knowledge and attitude, 0.028 for knowledge and practice, and $<0.001$ for attitude and practice, which indicate significant association between KAP towards smoking.

This shows that there is weak positive correlation between knowledge with attitude $(r=+0.193)$ and practice $(r=+0.206)$ regarding smoking, meaning higher knowledge scores is associated with higher attitude and practice scores (Figure 1 and 2 respectively). On the other hand, there is a moderate to good positive correlation between attitude and practice towards smoking $(r=+0.626)$ which indicates higher attitude scores correlating with higher practice scores (Figure 3).

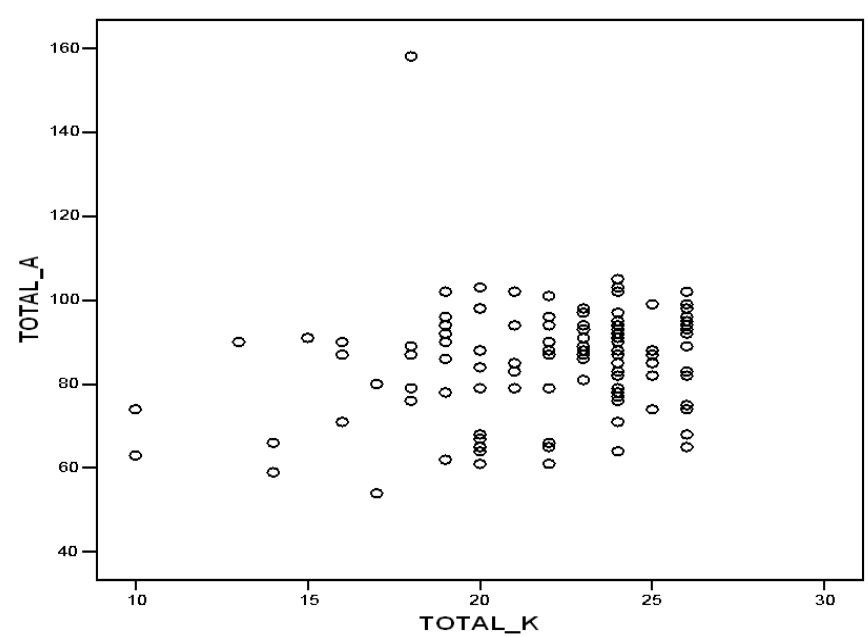

Figure 1. Correlation between knowledge and attitude scores

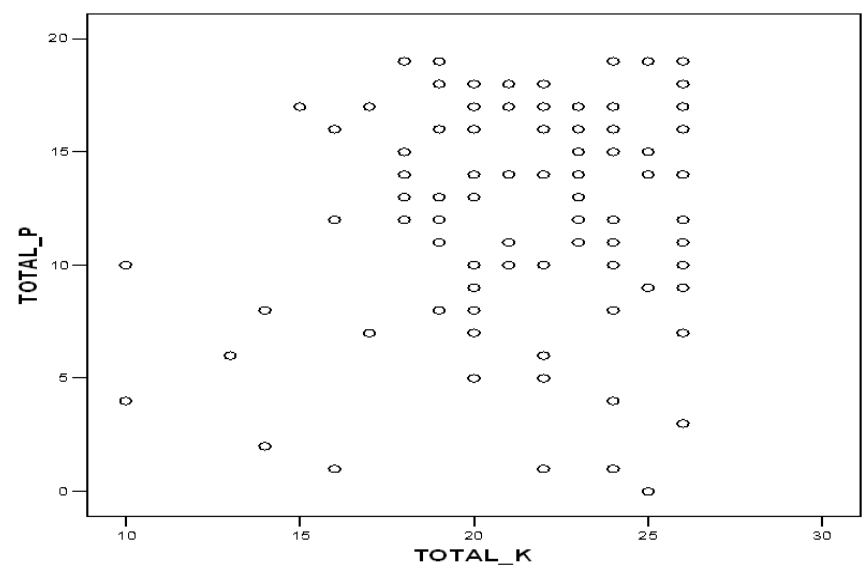

Figure 2. Correlation between knowledge and practice scores

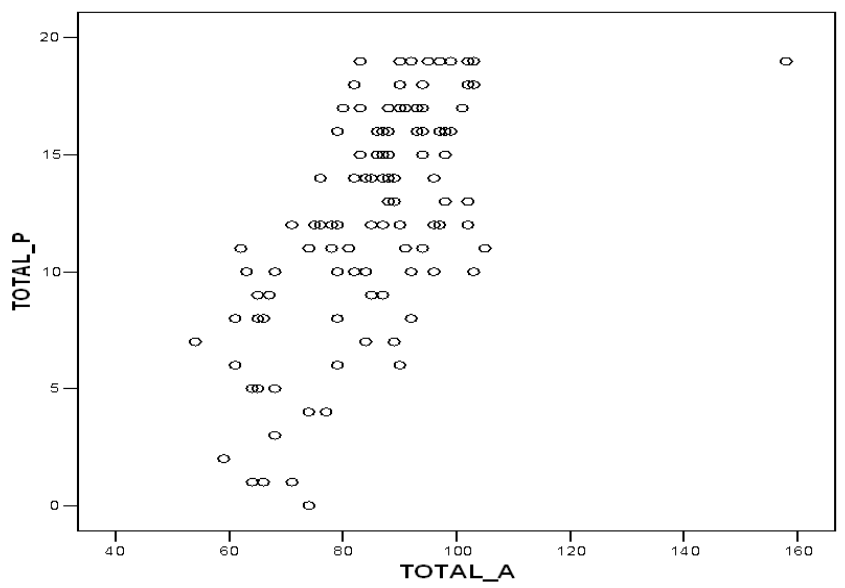

Figure 3. Correlation between attitude and practice scores 
Factors associated with knowledge and attitude towards smoking

This study found that gender was not associated with knowledge towards smoking. Even though the scores of knowledge for females $(n=58$, mean $=22.34 \pm 3.923)$ are higher as compared to males $(n=57$, mean= $21.42 \pm 3.923)$, the $p$-value of $0.152(t=-1.441, d f=113)$ meant that the difference was not statistically significant.

On the other hand, the $p$-value of $<0.001(t=-4.009$, $d f=87$ ) was obtained in the comparison of attitude scores between genders, meaning that there was a statistically significantly higher attitude scores of females (mean=90.91 \pm 8.755 ) as compared to males (mean=81.26 \pm 15.967$)$.

The non-parametric Spearman correlation test had been carried out in trying to find the association between knowledge and attitude regarding smoking with age. The $p$-values of $0.162(r=+0.162)$ and 0.573 $(r=+0.053)$ meant that there was no significant correlation between age with knowledge and attitude regarding smoking, respectively.

Comparison of knowledge scores towards smoking between different education levels, income and smoking statuses using Kruskall-Wallis test yield the $p$-values of more than 0.05 , which are $0.940,0.743$ and 0.124 , respectively (Table 1$)$. This means that there were no statistical significant differences in term of knowledge towards smoking in different levels of education, income or smoking statuses.

Table 1. Comparing knowledge scores regarding moking between different socio-demographic factors using Kruskall-Wallis test

\begin{tabular}{lccc}
\hline Variable & N & $\begin{array}{c}\text { Knowledge } \\
\text { scores } \\
\text { Median (iqr) }\end{array}$ & $\begin{array}{c}p- \\
\text { value }\end{array}$ \\
\hline Education Level & 28 & $22.50(7.000)$ & 0.940 \\
$\quad$ Secondary School & 21 & $23.00(5.000)$ & \\
$\quad$ Diploma & 66 & $23.00(4.000)$ & \\
$\quad$ Bachelor's Degree & & & \\
& & & \\
Income Status & 8 & $22.0(6.000)$ & 0.743 \\
$\quad$ Parents & 17 & $23.00(4.000)$ & \\
$\quad$ Loan or scholarship & 33 & $22.00(5.000)$ & \\
$\quad$ Salary less than RM1000 & $83.000)$ & \\
$\quad$ Salary RM1000-RM3000 & & $23.00(5.000)$ & \\
$\quad$ Salary RM3000-RM5000 & 8 & & \\
& & & \\
Smoking Status & 84 & $23.00(4.00)$ & 0.124 \\
$\quad$ Non smoker & 10 & $23.00(5.00)$ & \\
$\quad$ Former smoker & 21 & $20.00(8.00)$ & \\
$\quad$ Current smoker & & & \\
\hline
\end{tabular}

iqr = interquartile range

On the other hand, in comparing the attitude scores, the $p$-values were less than 0.05 in comparing between the different education levels $(p=0.016)$ and smoking statuses $(p<0.001)$, though the $p$-value was more than 0.05 for income status $(p=0.409)$, as summarised in Table 2 . Following that, the non-parametric Man-Whitney test was performed as the post-hoc test to find the significantly different pairs for comparing the attitude scores between different educational levels and smoking statuses. Using Bonferronni concept, the $p$-values obtained from this post-hoc test was compared to 0.017 $(0.05 / 3$ pairs) to find the significant pairs (Table 3$)$. It can be seen that there was a significant difference between the pair of secondary school leavers and diploma holders in term of attitude scores as the $p$ value is less than $0.017 \quad(p=0.004)$. For smoking status, using the same concept for post-hoc test, the significant difference was found between the pairs of non-smokers and current smokers $(p<0.001)$ and between former smokers and current smokers $(p=0.001)$ as summarised in Table 3.

Table 2. Comparing attitude scores towards smoking between different socio-demographic factors using Kruskall-Wallis test

\begin{tabular}{lcll}
\hline Variable & N & $\begin{array}{l}\text { Attitude } \\
\text { scores } \\
\text { Median (iqr) }\end{array}$ & p-value \\
& & & \\
\hline Education Level & 28 & $79.50(20.000)$ & 0.016 \\
$\quad$ Secondary School & 21 & $91.00(17.000)$ & \\
$\quad$ Diploma & 66 & $88.00(17.000)$ & \\
$\quad$ Bachelor's Degree & & & \\
Income Status & 8 & $82.00(31.00)$ & 0.409 \\
$\quad$ Parents & 49 & $88.00(16.00)$ & \\
$\quad$ Loan or scholarship & 17 & $86.00(25.00)$ & \\
Salary less than & 33 & $89.00(16.00)$ & \\
RM1000 & 8 & $92.00(14.00)$ & \\
$\quad$ Salary RM1000-RM3000 & & & \\
Salary RM3000-RM5000 & & & \\
& & & \\
Smoking Status & 84 & $90.50(12.00)$ & $<0.001$ \\
$\quad$ Non smoker & 10 & $87.50(14.00)$ & \\
Former smoker & 21 & $68.00(14.00)$ & \\
$\quad$ Current smoker & & & \\
\hline
\end{tabular}

iqr = interquartile range

Table 3: Multiple comparisons (post-hoc test) for comparing the attitude scores between different education levels and smoking statuses

\begin{tabular}{cccc}
\hline \multicolumn{3}{l}{ Pairs } & $p$-value** \\
\hline Education level: & & & \\
Secondary School & vs & Diploma & $0.004^{*}$ \\
Secondary School & vs & Bachelor's Degree & 0.031 \\
Bachelor's Degree & vs & Diploma & 0.258 \\
Smoking status: & & & \\
Nonsmoker & vs & Former smoker & 0.144 \\
Nonsmoker & vs & Current smoker & $<0.001^{*}$ \\
Former smoker & vs & Current smoker & $0.001^{*}$ \\
\hline
\end{tabular}

* Statistically significant difference as compared to 0.017 $(0.05 / 3)$ (Bonferronni concept)

${ }^{* *}$ Mann-Whitney test 
Comparing KAP towards smoking between students and workers

The independent $t$-test had been done to compare the level of KAP towards smoking among students and workers. The $p$-values were found to be 0.271 for comparing knowledge, 0.396 for attitude and
0.230 for practice. It can be concluded here that there was no statistical significant difference in terms of KAP between students and workers even though the mean values are higher for workers as compared to students (Table 4).

Table 4: Comparing knowledge, attitude and practice scores towards smoking, between students and workers using independent $t$-test

\begin{tabular}{|c|c|c|c|c|c|}
\hline Variables & $\begin{array}{c}\text { Students } \\
n=58 \\
\text { Mean (sd) }\end{array}$ & $\begin{array}{c}\text { Workers } \\
n=57 \\
\text { Mean (sd) }\end{array}$ & $\begin{array}{l}\text { Mean difference } \\
(95 \% \text { of } \mathrm{Cl})\end{array}$ & $\begin{array}{l}t \text {-stat. } \\
(d f)\end{array}$ & $p$-value \\
\hline \multicolumn{6}{|l|}{ (Scores) } \\
\hline Knowledge & $\begin{array}{l}21.53 \\
(3.643)\end{array}$ & $\begin{array}{l}22.25 \\
(3.242)\end{array}$ & $\begin{array}{c}0.711 \\
(-0.564,1.986)\end{array}$ & $\begin{array}{l}1.105 \\
(113)\end{array}$ & 0.271 \\
\hline Attitude & $\begin{array}{c}85.05 \\
(12.176)\end{array}$ & $\begin{array}{c}87.23 \\
(15.081)\end{array}$ & $\begin{array}{c}2.176 \\
(-2.883,7.236)\end{array}$ & $\begin{array}{l}0.852 \\
(113)\end{array}$ & 0.396 \\
\hline Practice & $\begin{array}{c}12.05 \\
(4.067)\end{array}$ & $\begin{array}{c}13.12 \\
(5.342)\end{array}$ & $\begin{array}{c}1.071 \\
(-0.687,2.829)\end{array}$ & $\begin{array}{l}1.208 \\
(105)\end{array}$ & 0.230 \\
\hline
\end{tabular}

\section{DISCUSSION}

\section{Association between KAP towards smoking}

The result shows that the overall knowledge regarding smoking was good where $63.5 \%$ of the respondents having good knowledge score, whereas the attitude towards smoking was moderate, and the practice towards prevention of smoking was also quite good. The result also shows significant positive correlation between knowledge and attitude, knowledge and practice, and also attitude and practice towards smoking.

The positive relationship could be interpreted as the high level of knowledge has resulted in the moderate to good level of attitude and practice towards smoking. This result was similar to the findings of one research report $^{7}$ which found the knowledge pertaining smoking was predictive of the attitude towards smoking, and it leads to effective tobacco control.

However, the strength of association between attitude and practice was higher as compared to the strength of association between knowledge and attitude, and between knowledge and practice towards prevention of smoking. Thus, the levels of attitude and practice towards smoking were still dependent on knowledge, but the practice towards prevention of smoking was more prone to be affected by the level of attitude.

The high level of knowledge regarding smoking was expected as the environment of the university is medically based and they were prone to be exposed to the negative effects related to smoking. Majority of them knew that most of the chemicals in a cigarette are toxic, and that it contains nicotine. Moreover, almost all respondents were aware of involuntary or second-hand smoke.
The level of attitude was moderate among students and workers. There were varying attitudes towards smoking as there were differences between the attitude of the smokers, non-smokers, and former smokers. Attitude towards smoking is essential as it plays an important role in the initiation and maintenance of self-motivated smoking. An opposite finding has been reported from China which when compared with the current study, there was a stronger anti-smoking attitude among medical students. ${ }^{12}$ The statement about smoking giving satisfaction and releasing stress were among the highest negative attitude found in this study. In contrast, the statement about smoking which can lead to many negative health effects was among the highest positive attitude towards smoking. A previous study conducted identified that the most common attitudes towards smoking were the enjoyment of smoking, boredom, habit, and stress. ${ }^{9}$ Some of the respondents in this current study also agreed that smoking might lead to psychological addiction.

This study also detected that a high level of practice towards prevention of smoking. It was found that $68.7 \%$ of respondents preferred to move away from the smoking area. This maybe due to their high level of knowledge regarding the negative effects of smoking, not only to the smoker him/ herself, but also to the surrounding people. Furthermore, one respondent from a previous qualitative study stated that she will never smoke around children or people who are non-smokers. ${ }^{9}$

Association of Socio-Demographic Factors with Knowledge towards Smoking

There was no significant association between all socio-demographic factors with the knowledge 
towards smoking, which means the level of knowledge were similar regardless of their gender, age, education level, income status and smoking status. This result may be due to people who were more alert and conscious about health. Therefore, they might have interest to learn the health-related knowledge regardless of their varied background. Even though there was no association between gender and knowledge towards smoking, the level of knowledge of females was relatively higher. The current finding is different from a previous study ${ }^{13}$ which found that knowledge among the young women was relatively poor.

The knowledge towards smoking for each education level of secondary school, diploma, and bachelor holders were similar in their mean score values. This result is different as compared to another study which reported that people with lower education level possess less knowledge about smoking. ${ }^{13}$ The results from current study may be due to IIUM's strict policy and practices of quality healthy lifestyle. Furthermore, there was also no significant relationship between knowledge and income status. The study respondents may have non-formal education regarding smoking, irrespective of their income status. Most of the respondents were familiar and enthusiastic to learn more about the disease related to smoking.

It seems that the lack of association between knowledge and smoking status was supported by another previous study. ${ }^{13}$ They found that there was no difference in the level of knowledge regarding adverse effects of smoking among smokers and nonsmokers. Review from another previous study also concluded that the knowledge as regards to adversarial effects of smoking, but pleasure, enjoyment, obsession and overcoming stress, compel them to smoke. ${ }^{14}$ In addition, majority of smokers knew the negative consequences of smoking on their own, but they were not concerned and were confident in maintaining their good health. ${ }^{15}$ The intention to quit smoking was strongly associated with the desire to escape the impending tribulations and benefits of a nonsmoking lifestyle. ${ }^{16}$

Association of Socio-demographic factors with Attitude towards Smoking

There was a significant difference in terms of attitude towards smoking between males and females. The mean value of females' attitude scores regarding smoking was higher as compared to males. The study in Hong Kong found similar results as they identified woman had positive attitudes towards tobacco control program. ${ }^{17}$ They even concluded that the positive attitude leads to successful law enforcement of anti-smoking in their country. In the present study, the attitude of females was higher than males may be because of the nature that smoking is more prevalent in males. Other than releasing stress and give satisfaction, males may tend to have the attitude that smoking can increase their work performance, and some of them think that smoking is a symbol of attraction to women. Another plausible explanation from other studies is that Malaysian's males have lack of perception regarding the harmful effects of tobacco and that cigarettes were very affordable and easily available. ${ }^{5}$

A significant difference was also observed in terms of attitude towards smoking between different smoking statuses. From the post-hoc test, the differences were observed between non-smokers and current smokers, and between former smokers and current smokers. Similar results from another study also stated that smoking status is a major predictor of attitude towards tobacco control. ${ }^{7} \mathrm{~A}$ respondent in another study apprehended that stop smoking may lead to the smokers loosing his/her social group. ${ }^{9} \mathrm{~A}$ study suggested that it is not easy to convince the general population that smoking gives despicable effects on their health. ${ }^{18}$

Moreover, there was a significant difference in terms of attitude towards smoking between different education levels. In specific, the significant pair was between the secondary school leavers and diploma holders. The result shows higher level of attitude in those with higher level of education. However, the attitude may also depend on the early exposure and education that starts from home. This result was supported by the findings from a previous study ${ }^{13}$ and a report from Morbidity and Mortality Weekly Report $(M M W R)^{19}$ which found that high level of education do increase the reduction in smoking related attitudes. Unfortunately, there was no significant association between attitude and age. Another study reported that age levels play an important role in the perceptions towards smoking. ${ }^{5}$ The increasing age will indirectly expose them to encounter smoking related health problems, and tends to make these people more receptive to public health messages. ${ }^{5}$

Most of the previous studies conclude that income status may affect the level of attitude towards smoking. The result of this study shows that the group with the salary of between RM3000-RM5000 had the highest positive attitude towards smoking, followed by those with the salary below that, followed by those on scholarships and those supported by parents. This could have some relationship with their education levels. However, this result was not significant statistically. A study indicated that almost $40 \%$ of Malaysian and $49 \%$ of Mauritius smokers feel that smoking is a burden for their finances. ${ }^{5}$ Thus, in this present study, the respondents might feel the burden and slightly affects their attitude towards smoking.

\section{Level of KAP towards Smoking among Students and Workers}

Students were assumed to have a higher level of KAP towards smoking as compared to workers. However, the result of this present study shows that there was no significant difference in terms of KAP between 
students and workers. This result may due to the same environment of students and workers in this university as IIUM campus is a strictly "No-Smoking" campus. Thus, students and workers may indirectly have high concerns towards smoking. However, the mean values were still higher for workers as compared to students. This may due to several differences in the socio-demographic factors between workers and students. As stated in a previous study in many Western countries, smoking related knowledge is strongly associated with the disparities of socioeconomic status. ${ }^{20}$ The disparities of socioeconomic status also led to the differences in reception toward such policies such as supporting the restrictions on smoking in indoor public places.

In this study, the range of age was from 30-40 years old for workers and early twenties for students. The variety of age levels might characterise the level of understanding towards the health hazards of smoking and receptivity to medical advice. ${ }^{5} \mathrm{~A}$ study in Nepal found out that young adults have the knowledge but lack of awareness of its addictive nature. ${ }^{21}$ They might have less concern about the health consequences because they think that they can quit smoking easily and at any time. Most of the workers who participated in this present study were in the management section who faces low physical and psychosocial stressors as compared to elementary and agricultural workers. ${ }^{5}$

\section{Other Associated Factors Related To Smoking Behavior}

Apart from the socio-demographic factors, many other associated factors had been explored in other studies which might be the fuel to build up the interest regarding smoking. In specific, this present study found out that the highest percentage for the negative attitude towards smoking was getting the satisfaction in smoking, followed by releasing stress and controlling body weight. Next, some respondents agreed that smoking can increase their work performance and social acceptability, whereas smoking as the symbol of attraction, glamorous and modern were agreed by only less than $10 \%$ of the respondents. The opinion that smoking can give satisfaction and release stress is supported by another study. ${ }^{14}$ Students may tend to face a stressful condition in studies and they may release it by smoking, which also provides some pleasure and relaxation. ${ }^{14}$ Furthermore, workers may look at smoking as one of the ways to rest after a tiring condition of working hours. "If you're at work, and you smoke, you tend to get a lot more breaks at work".

Regarding the attitude that smoking helps to control body weight, another study had similar results which focus more on young adults. Asian women were becoming the target of Western ideals of thinness and glamour. ${ }^{21}$ Fortunately, this current study indicates that students and workers did not smoke to be attractive, modern or glamorous. IIUM pays serious attention not only to the academic needs of students, but also their spiritual and moral life. Furthermore, the university promotes anti-smoking policy. Some regular smokers opined that they get happiness and enjoying the smoking habit rather than give it up as they get older. ${ }^{9}$

\section{Preventive and Control Measures Regarding Smoking} The respondents in this study were also asked regarding their general opinion of the ways to overcome the increasing smoking prevalence in Malaysia. Our results suggested that the best way to reduce smoking prevalence is by increasing the price of cigarettes, which is supported by multiple studies. ${ }^{3,9}$ The 'culture of tolerance' has been the most frequently cited barrier to implementing smokefree policy. ${ }^{22}$ Strong public support is required to apply the smoking ban in Malaysia by emphasising the negative effects of smoking on human health.

The result shows the need to discontinue the importation and selling of cigarettes in Malaysia. The importation of tobacco as one of the huge sources of economy's profit for the countryis a chief hurdle. Malaysia should be strict in the enforcement of the law, especially regarding underage smoking. In Malaysia, cigarettes are too easily available and affordable by smokers that contribute to increase cigarettes purchasing. Some respondents also suggested that media exposure plays an important role in shaping the positive attitude. Malaysia have a number of anti-smoking programs which includes a five-year national campaign with the slogan 'Tak Nak' (Say No) which have reached more than $92 \%$ of the population. ${ }^{5}$ These programs should be continued with more emphasis to the younger generation, as early education is quite important.

Finally, other preventive methods to be considered may include altering the taste and packaging of cigarettes to be not user-friendly, alternative treatment program for the smoking cessation, promoting healthy lifestyles and providing less stressfull environment to discourage smoking. Unfortunately, the point of hidden sale displays and packaging of cigarettes were said to give little effect on cigarette purchasing to established smokers as compared to younger smokers. ${ }^{9}$

\section{CONCLUSION}

This study found positive correlation between KAP towards smoking and the respondents have good knowledge, moderate attitude and good practice towards smoking. Furthermore, there was a significant association between attitude towards smoking with the socio-demographic factors, namely genders, education level and smoking status. Also, the present study found that there was no significant difference in terms of KAP between students and workers. 


\section{ACKNOWLEDGEMENT}

Authors are much grateful to the students and workers who participated in this study in between their busy schedule. Authors are also grateful to IIUMK authority to allow the conduct of this study.

\section{REFERENCES}

1. Lim KH, Sumarni MG, Kee CC, Norhamimah A, Wan Rozita WM, Amal NM. Prevalence, Smoking Habit And Factors Related To Smoking And Nicotine Addiction Among Lower Secondary School Male Students In Kota Tinggi District, Johor, Malaysia. Malaysian Journal of Public Health Medicine 2010;10:28-37.

2. World Health Organization. Trade, Foreign Policy, Diplomacy, and Health. Tobacco. http://www.who.int/trade/glossary/story089/ en/

3. World Health Organization (WHO). Media Centre. Tobacco. Fact sheet No 339. Updated July 2015. http://www.who.int/mediacentre/ factsheets/fs339/en/

4. Hosking $\mathrm{W}$, Borland R, Yong $\mathrm{HH}$, Fong $\mathrm{G}$, Zanna M, Laux F, Thrasher J, Lee WB, Sirirassamee B, Omar M. The effects of smoking norms and attitudes on quitting intentions in Malaysia, Thailand and four Western nations: A crosscultural comparison. Psychol Health 2009;24:95-107.

5. Lim HK, Ghazali SM, Kee CC, Lim KK, Chan YY, Huey CT, Yusoff AFM, Kaur G, Zain ZM, Mohamad MHN, Salleh S. Epidemiology of Smoking among Malaysian adult males: prevalence and associated factors. BMC Public Health 2013;13:1-10.

6. Torabi MR, Yang J, Li J. Comparison of Tobacco Use Knowledge, Attitude, and Practice among College Students in China and United States. Health Promot Int 2002;1:247-53.

7. Blake KD, Viswanath K, Blendon RJ, Vallone D. The role of tobacco-specific media exposure, knowledge, and smoking status on selected attitudes toward tobacco control. Nicotine \& Tobacco Research 2010;12:117-26.

8. Institute for Public Health (IPH). Report of the Global Adult Tobacco Survey (GATS) Malaysia, 2011, Ministry of Health Malaysia, 2012. http://www.who.int/tobacco/surveillance/surv ey/gats/malaysia_country_report_2011.pdf

9. Uppal N, Shahab L, Britton J, Ratschen E. The forgotten smoker: a qualitative study of attitudes toward smoking, quitting, and tobacco control policies among continuing smokers. BMC Public Health 2013;13:1-9.

10. Taylor T, Cooper TV, Hernandez M, Kelly M, Law J, Colwell B. A Smoke-Free Paso del Norte: Impact Over 10 Years on Smoking Prevalence Using the Behavioral Risk Factor Surveillance System. Am J Public Health 2012;102:899-908.

11. Aryal UR, Petzold M, Krettek A. Perceived risks and benefits of cigarette smoking among Nepalese adolescents: a population based cross-sectional study. Public Health, 2013;13:19.

12. Han $M Y$, Chen $W Q$, Wen $X Z$, Liang $C H$, Ling $W H$. Differences of smoking knowledge, attitudes, and behaviors between medical and non-medical students. Int J Behav Med 2012;19:104-10.

13. Manaf RA, Shamsuddin K. Smoking among Young Urban Malaysian Women and its Risk Factors. Asia Pac J Public Health 2008;20:204-13.

14. Babatunde OA, Omowaye OA, Alawode DA, Omede O, Olomofe CO, Akiyandenu J. Smoking prevalence, willingness to quit and factors influencing smoking cessation among University Students in a Western Nigerian State. Asian Social Science 2012;8:149-156.

15. Sansone GC, Route LJ, Fong GT, Pednekar MS, Quah ACK, Travers MB, Gupta PC, Sinha DN. Knowledge of Health Effects and Intentions to Quit Among Smokers in India: Findings From the Tobacco Control Policy (TCP) India Pilot Survey. Int J Environ Res Public Health 2012;9:564-578,

16. Borland R, Yong HH, Balmford J, Cooper J, Cummings KM, O'Connor RJ, McNeill A, Zana, MP, Fong GT. Motivational factors predict quit attempts but not maintenance of smoking cessation: Findings from the International Tobacco Control Four country project. Nicotine Tob Res 2010;12(Suppl 1): S4-S11.

17. Leung DYP, Chan SCC, Fu ICY, Lam TH. Knowledge, attitudes and practices regarding smoking cessation among Chinese affiliates of women's organizations in Hong Kong. Health and Social Care in the Community 2011;19:207-16.

18. Stojanovic M, Musovic D, Petrovic B, Milosevic Z, Milosavljevic I, Visnjic A, Sokolovic D. Smoking habits, knowledge about attitudes toward smoking among employees in health institutions in Serbia. Vojnosanit Pregl 2013;70:493-500.

19. Centre for Disease Control and Prevention. Current Cigarette Smoking among Adults age $>18$ years old. Morbidity and Mortality Week Report (MMWR) 2009;59,1135-40. Retrieved from http://www.cdc.gov/mmwr/preview/mmwrhtm l/mm5935a3.htm

20. King BA, Hyland AJ, Borland R, McNeill A, Cummings KM. Socioeconomic Variation in the Prevalence, Introduction, Retention, and Removal of Smoke-Free Policies among Smokers: Findings from the International Tobacco Control (ITC) Four Country Survey. Int J Environ Res Public Health 2011;8:411-434,

21. Parkinson CM, Hammond D, Fong GT, Borland R, Omar $M$, Sirirassamee $B$, Awang $R$, Driezen $P$, Thompson M. Smoking beliefs and behavior among youth in Malaysian and Thailand. Am J Health Behavior 2009;33:366-75.

22. Movsisyan NK, Thompson ME, Petrosyan V. Attitudes, practices and beliefs towards worksite smoking among administrators of private and public enterprises in Armenia. Tobacco Control 2010;19:274-8. 